\title{
Design and implementation of a three dimensions (3D) printer for modeling and pre-manufacturing applications
}

\author{
Ghazi Qaryouti' ${ }^{1}$, Abdel Rahman Salbad ${ }^{2}$, Sohaib A. Tamimi ${ }^{3}$, Anwar Al-Mofleh", \\ Wael A. Salah ${ }^{5}$, Qazem Jaber ${ }^{6}$ \\ 1,2,3,6 Department of Mechatronics Engineering, Al-Balqa' Applied University, Jordan \\ ${ }^{4}$ Faculty of Engineering Technology, Al-Balqa' Applied University, Jordan \\ ${ }^{5}$ Department of Electrical Engineering, College of Engineering and Technology, \\ Palestine Technical University-Kadoorie (PTUK), Palestine
}

\begin{tabular}{|c|c|}
\hline Article Info & ABSTRACT \\
\hline $\begin{array}{l}\text { Article history: } \\
\text { Received Feb 16, } 2019 \\
\text { Revised May 6, } 2019 \\
\text { Accepted Jun 26, } 2019\end{array}$ & $\begin{array}{l}\text { The three-dimensional (3D) printing technologies represent a revolution in } \\
\text { the manufacturing sector due to their unique characteristics. These printers } \\
\text { arecapable to increase the productivitywithlower complexity in addition tothe } \\
\text { reduction inmaterial waste as well the overall design cost prior large } \\
\text { scalemanufacturing.However, the applications of 3D printing technologies }\end{array}$ \\
\hline $\begin{array}{l}\text { Keywords: } \\
\text { 3D printing } \\
\text { Applications } \\
\text { Energy } \\
\text { Environmental } \\
\text { Manufacturing }\end{array}$ & $\begin{array}{l}\text { unexplored field due to their high complexity. In this paper the development } \\
\text { of } 3 \mathrm{D} \text { printing technologies for the manufacture of functional parts and } \\
\text { devices for different applications is presented. The use of } 3 \mathrm{D} \text { printing } \\
\text { technologies in these applicationsis widelyused in modelingdevices usually } \\
\text { involves expensive materials such as ceramics or compounds. The recent } \\
\text { advances in the implementation of 3D printing with the use of environmental } \\
\text { friendly materialsin addition to the advantages ofhighperformance and } \\
\text { flexibility. The design and implementation of relatively low-cost } \\
\text { and efficient 3D printer is presented. The developed prototype was } \\
\text { successfully operated with satisfactory operated as shown from the printed } \\
\text { samples shown. }\end{array}$ \\
\hline
\end{tabular}

Copyright $\odot 2019$ Institute of Advanced Engineering and Science. All rights reserved.

\section{Corresponding Author:}

Anwar Al-Mofleh, Department of Electrical Engineering, Faculty of Engineering Technology, Al-Balqa' Applied University, MarkaAshamalia, Jordan.

Email: anwaralmofleh@yahoo.com

\section{INTRODUCTION}

The term three dimensions (3D) printersmostly linked totechnologies such as: rapid prototyping (RP), direct digital manufacturing (DDM), layered manufacturing and 3D printing. The whole group of 3D printers isrelated to the development and modellingof different objects by printing them in layer form. The history of this technology is yet up to date. Throughoutwhich a various names had been assigned including stereo lithography, 3D laying and the 3D printing that is commonly used term. The additive manufacturing (AM) is a term to describe set of technologies that produce $3 \mathrm{D}$ objects by adding layering the material at different upon - layer form. The used materials can vary based on the prototype to be produced. But there are some common features for all Additive manufacturing, such as usage of computer together with special 3D modeling softwaretools.

The first step of the 3D modellingprocess is to create computer aided design (CAD) design sketch. Afar that AM device reads data from CAD file and builds a structure layer.The use of thinner layers is most noticeable in the surface finish of prints with diagonal or curved surfaces. Theresolution of the developed 
model generally determined by these thin layers.In addition thethickness value of each layer is mostly determined and defined in specification sheets.

A study revives the uses of 3-D printing compared with other pre mas manufacturing techniques is presented [1]. It shows that 3-D printing allows products customization especially when produced at low quantities at relatively low cost. This rowing in use technology enables consumers to be able to order their customized designs online at reasonable costs. In addition, it enables the companies to maneuver at very low or no unsold finished goods inventory. As well the 3-D could considerably reduce the producing small lot sizes in low-wage countries via reduced need for factory workers [1]. A study showed that the product map for 3D printing products provides a reference system for evaluating products and their suitability for printing. Also the business leaders could localize their product to determine if it is in a region where additive manufacturing is likely to provide an advantage over conventional manufacturing. The $3 \mathrm{D}$ printing could be considered a technology with low-cost customization levels [2].

Most Fused Deposition Modeling (FDM) printers consumer claim standard printing heights of between $(0.1-0.3) \mathrm{mm}$ although the Ultimate 2 , which is considered a high resolution desktop 3D printer, boasts of a (0.02) $\mathrm{mm}$ layer height.According to high quality 3D printers manufacturers, 3D printer with $(0.1-0.3) \mathrm{mm}$ layer resolution comes at a range of (1000 - 3000) dollar, this high cost limits the ability of ordinary people to buy their own 3D printer and as a result, this limits the accessibility of this technology to the world. Large extent of real-time data of product manufacturing cycle (PMC) requires to be properly evaluated. The architecture of data analytics for product manufacturing cycle of fused deposition modeling (FDM) technique of 3D printing was proposed [3]. The proposed architecture realizes the design modeling data accessibility and 3D printing product could be easily implemented.

The use of new developed digital electronics such as microcontrollers enable the in integration of the 3D printers with Internet of Things (IoT) [4]. These technologies connect everything in the smart world daily. It is found to be the key technology developed to realize for a wide range of IoT applications such as smart homes in addition toautomatedindustrial applications [5]. Therefore the components used to implement the $3 \mathrm{D}$ printers to be compatible to easy integrate with. Thought the wide use of BLDC motors due to their feature and digitally controlled drives became among the choices to be considered throughout the design process [6].

The construction industry is highly dependent on various parameters affecting the implementation of the 3-D printing. The main parameters include accuracy, printing materials availability, the cost, and printing time. On the other hand various benefits can be achieved such as the waste reduction, flexible design and reduced manpower which could compensate some of printing cost. Yet, still some limitations arises like the applicability in large-scale projects and the life cycle cost of 3-D printed construction projects as the life cycle performance of the printed projects still unclear. Once these limitation are addressed in the next genratiion of the $3 \mathrm{D}$ construction printers the 3-D printing consider as a potential technology in construction industry [7].

A 3D printer prototype successfully developed and fully-integrated system which incorporates a mechanical plant, electronics, drivers, embedded controllers, and software interface is realized. The presented prototype is used as an educational reference for mechatronics design devices printers [8]. The 3D printers are explored are integrated and used in many application nowadays which are not limited to industrial and pre-manufacturing only. The aim of this paper is to propose the design and implementa high resolution 3D printer. The related system components including the mechanical system, electrical system and control system is realized in relatively cheap and simple comparing to same technology commercially available.The mentioned different design and implementation steps of the developed 3D device are presented in details in the following sections.

\section{3D PRINTER DESIGN AND MANUFACTURING}

Simulate and build of a particular design is carried out utilizinga specialized computer program. The built of an imagination particular designshould go to the following step of the proposed design. This can be easily realized oncebuilding a simulated model on a specialized computer program like Solidworkswhich used in this research.The Solidworkssoftware is a mechanical design automation tool that aids tosketch out ideas quickly. Also this tool could experiment the design with itsfeatures and dimensions to produce models and detailed drawings as shown in Figure 1 which shows the proposed 3D printer design.

As shown, from the 3D model of the design, the designer canget a clear perspective about the design shape, motion simulation, precise dimensions for each component as well a strong background to implement the design in real world. So, this step is an important step to successful implement anengineering design and engineering work. Moreover, this reduces the cost of waste components, time and money 


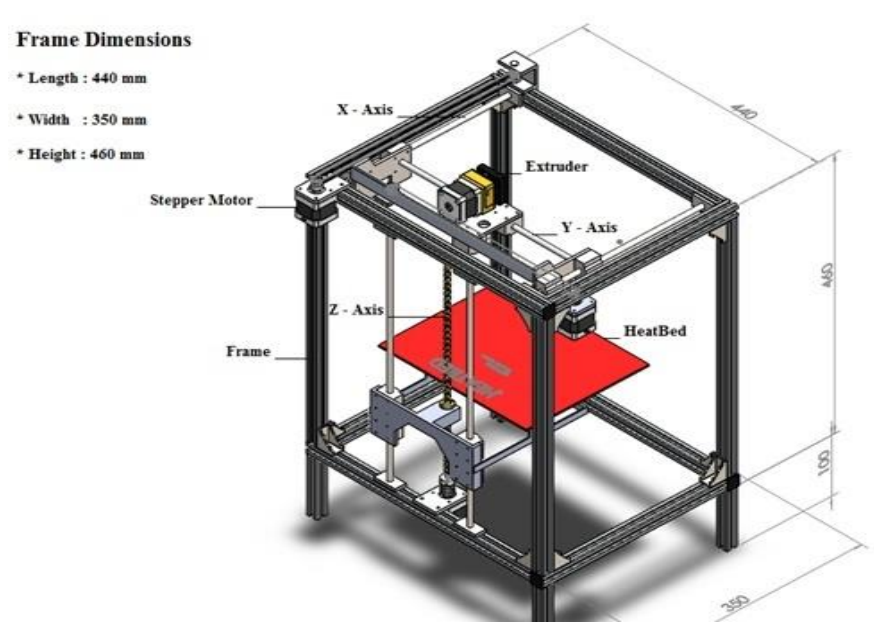

Figure 1.3D model isometric projection

\section{DESIGN IMPLEMENTATION OF 3D PRINTER}

Manufacturing and implementing the design in real world is the process that starts from getting the first component which is the frame, assembling mechanical, electrical and control systems, to getting the final product as follow:

Starting with the frame, the frame should be made and assembling according to the shape and precise dimensions taken from 3D model of the design.The frame was made from Iron as shown in Figure 2 with small dimensions error percentage that does not exceed a few millimeters which is an acceptable one. The real frame dimensions were: Length: $442 \mathrm{~mm}$, Width: $353 \mathrm{~mm}$ and Height: $461 \mathrm{~mm}$.

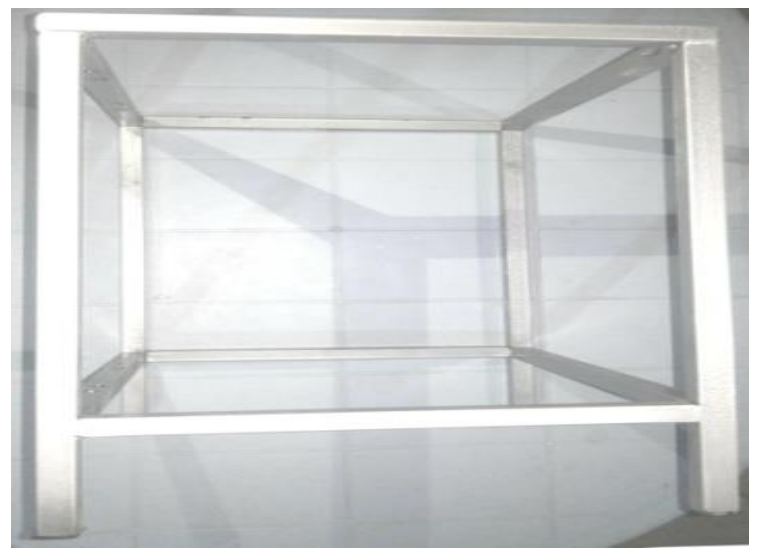

Figure 2. 3D printer iron frame

The following step is the mounting linear bearing, axes linear shaft and linear bearing shaft support. the linear bearing, which has $(8 \mathrm{~mm})$ bore diameter, is mounted to $\mathrm{X} \mathrm{Z}$ axes linear shafts that has the same shaft diameter, then holding linear bearing shaft supports $(8 \mathrm{~mm}$ bore $)$ to frame. Then mounting the combination of linear bearing and axes linear shafts to linear bearing shaft supports as shown in Figure 3. This process should calibrate precisely to result in two parallel facing axes linear shafts to satisfy linear bearings sliding motion.

The solid componentsas shown in Figure 4 are formedin a specific shape and dimensions to satisfy the design requirements. Such requirementslike fixing stepper motors with frame to hold the 3D printer extruder, Y axis linear shaft and heat (Print) bed.

Thestepper motors and mechanical transmission systems installation are shown in Figure 5. The X Y Z stepper motors installation process had done by mounting these stepper motors to frame using a specifically design solid components. 


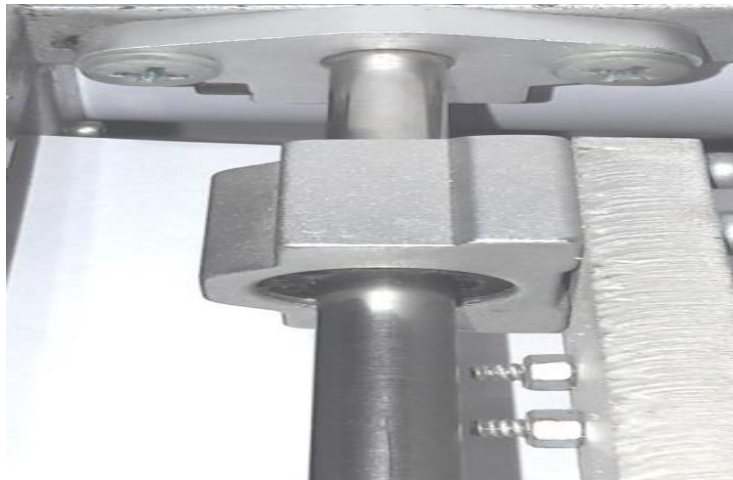

Figure 3. Axes linear shaft, linear bearing and shaft support combination

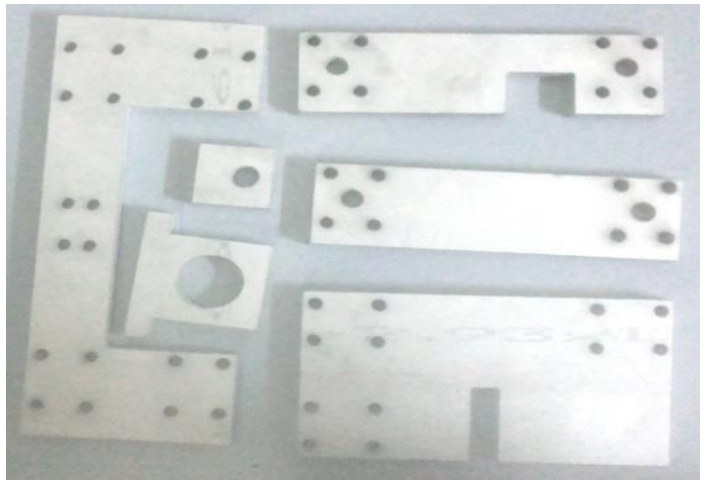

Figure 4.Solid components

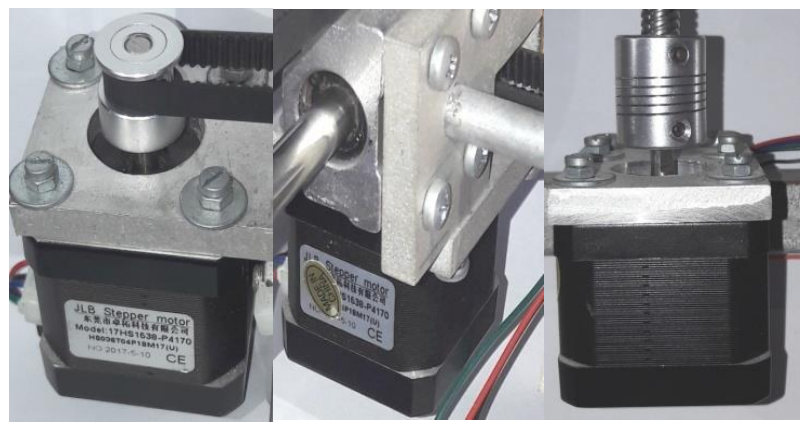

Figure 5. X Y Z stepper motors

After illustrating the stepper motors, then installingthe components that used to transmit the motor power to the load which is the mechanical transmission system. Two types of mechanical transmission systemsare used:

a. $\quad$ Belt, pulley and idler pulley mechanical transmission system:

This type of mechanical transmission system is used in our design for $\mathrm{X}$ and $\mathrm{Y}$ axes (for horizontal movements) as shown in Figure 6. This system consists of (GT2) timing belt with (6 mm) rubber width, (GT2) timing pulley and idler pulley with $(5 \mathrm{~mm})$ Bore, $(20$ teeth) and $(10 \mathrm{~mm})$ width.

b. Lead Screw and Nut mechanical transmission system:

This type of mechanical transmission system is used in our design for $\mathrm{Z}$ axis (for vertical movement) as shown in Figure 7. This system consists of $(400 \mathrm{~mm})$ length, $(8 \mathrm{~mm})$ shaft diameter Stainless steel lead screw with $(2 \mathrm{~mm})$ pitch and copper nut.

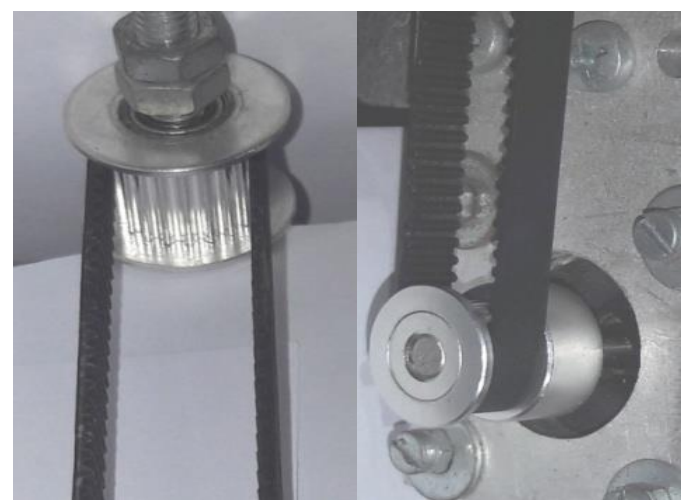

Figure 6. Belt, pulley and idler pulley mechanical transmission system

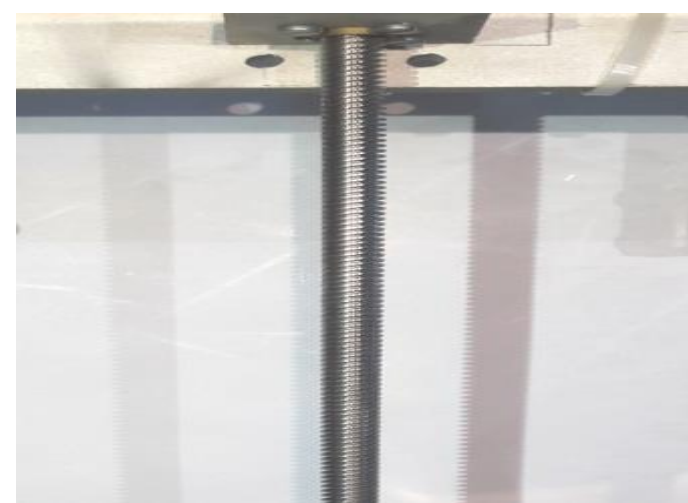

Figure 7. Screw and nut mechanical transmission system 
In this system, the linear motion is implemented by rotating the lead screw and this rotation will push the Nut up and down according to the direction of rotation. After that the installation and construct the electrical and control systems is taken place in the design 3D printer system. This process includes mounting (A4988) stepper motor drivers to the ReprapArduino Mega Pololu Shield (RAMPS). Then mounting this combination to Arduino Mega 2560 controller as shown in Figure 8. Thereafter thewiring should be done according to schematic wiring diagram and schematic detailed drawing of these components that are referred to manufacturing company as shown in Figure 9.

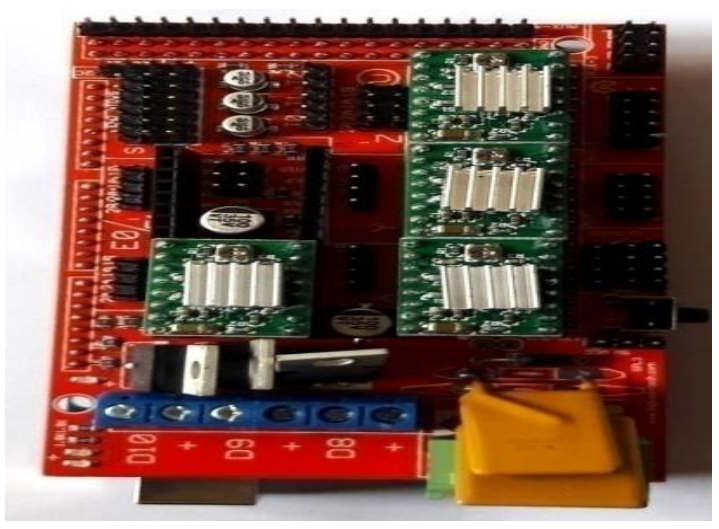

Figure 8. Construction of control system

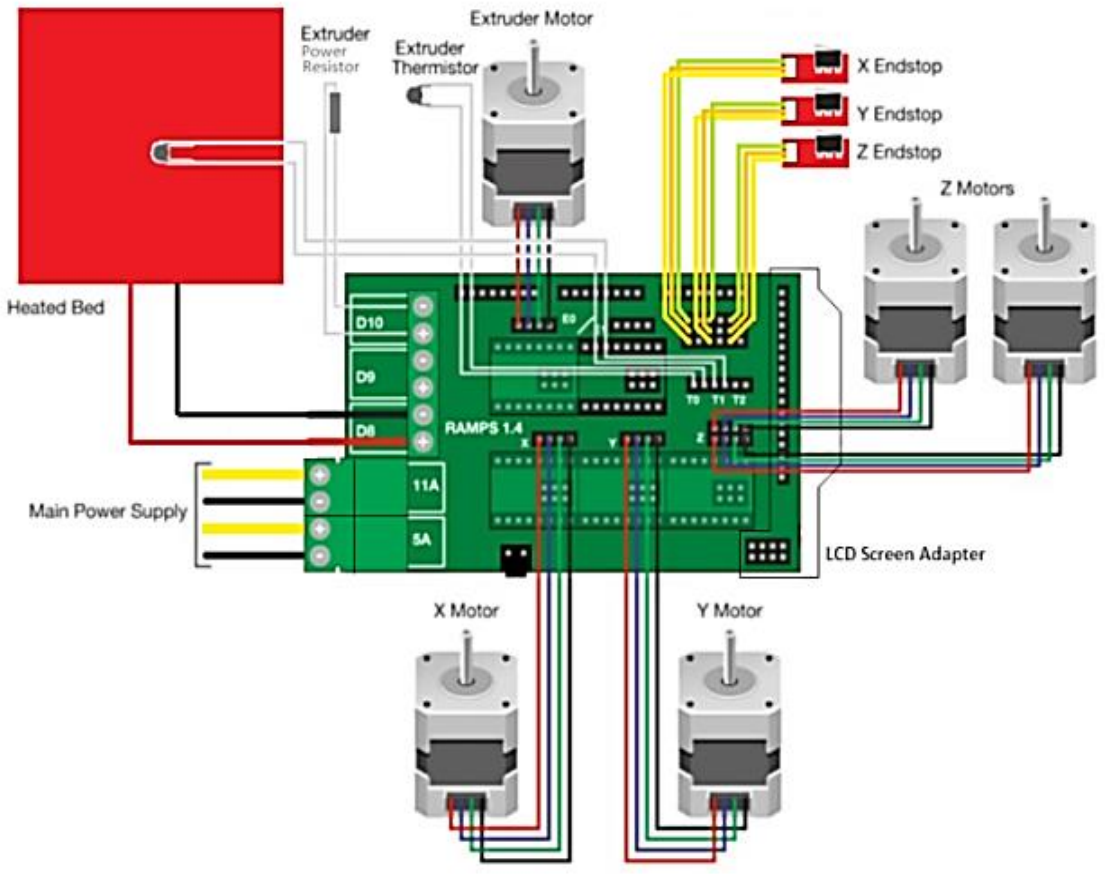

Figure 9. Schematic wiring diagram of 3D printer electrical system

After that the installation of the limit switches to 3D printer body is realized. The minimum position limit switches are installed to 3D printer body as shown in Figure 10. The switch is used to indicate the point that any printing process starts from (Homing position or minimum position). This installation process plays a major rule in limitation the printing area dimensions, since the maximum position of axis maybe taken relative to minimum limit switch which can be defined in firmware or by installing another limit switch to indicate the maximum position. 


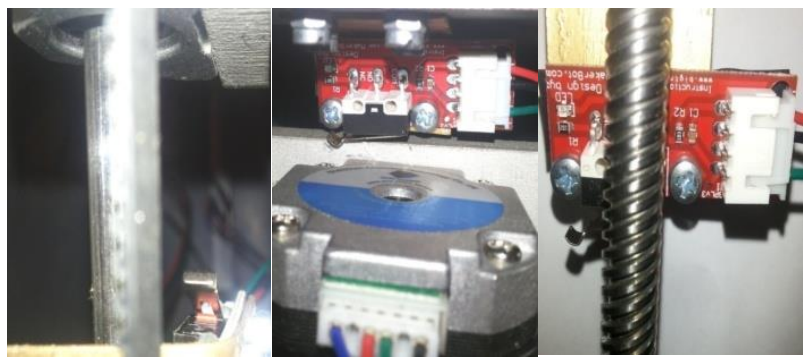

Figure 10. X Y Z limit switches construction

Finally, the mounting the extruder and heat bed is carried out. The extruder and heat bed can be mounted in different ways and to different axes. In the presented design theextruder is mounted to $\mathrm{Y}$ axis and Heat Bed is mounted to the $\mathrm{Z}$ axis as shown in Figure 11 and 12.

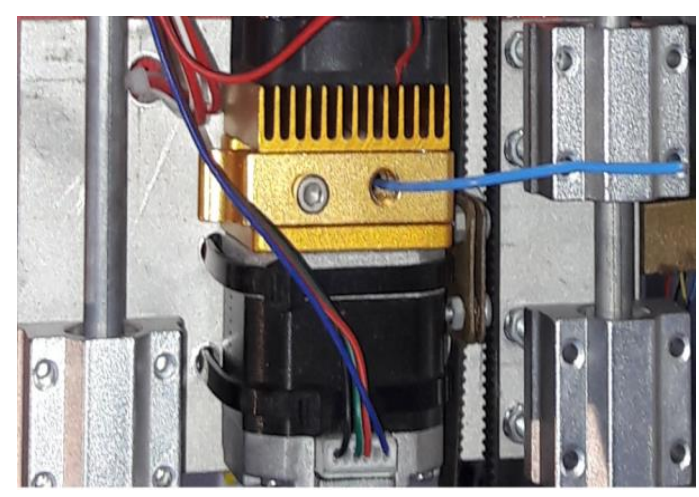

Figure 11.3D printer extruder

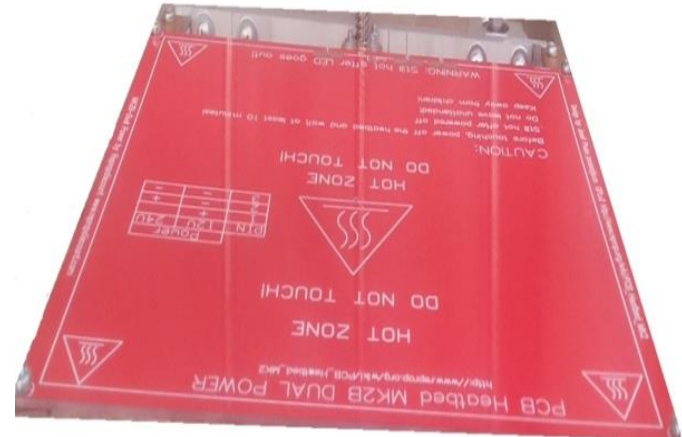

Figure 12. 3D printer heat bed

\section{3D Printer Conditioning for Operating}

First step in conditioning 3D printer for operation is uploading the firmware to Arduino Mega 2560 controller by using Arduino Integrated Development Environment (Arduino IDE) computer software. This firmware will govern and control the 3D printer systems.After uploading firmware to the controller, we should find a way to communicate with 3D printer, which can be achieved by two ways:

A. Using computer software:

Using computer software, which is serially communicated with $3 \mathrm{D}$ printer using serial communication port, is the best choice for 3D printer users because it provides more option rather than using LCD.

B. Using Liquid Crystal Display (LCD) Smart controller interface:

Using Liquid Crystal Display (LCD) smart controller interface, as shown in Figure 13, is used as secondary method to communicate and shows the most important printing process parameters of $3 \mathrm{D}$ printer.

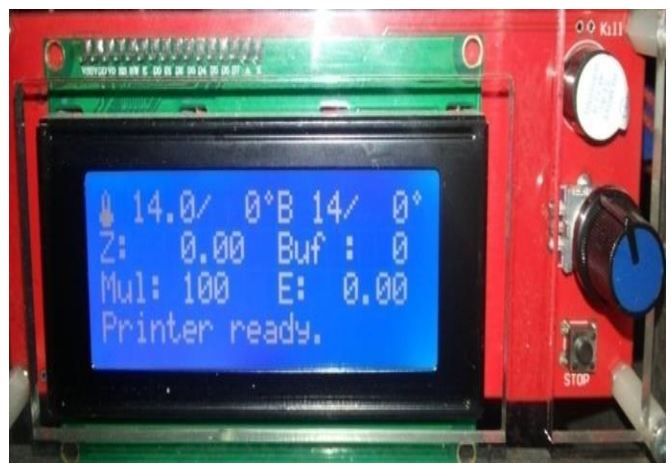

Figure 13. LCD smart controller interface 


\section{3D PRINTER CALIBRATION}

The steps to calibrate the printer could be listed as:

a. Get the 3D model in the following file extensions: "A. .stlfiles . B. .astfiles . C. .3mf files". D. .obj files. E. .gcode files. F. .gcofiles. G. .g files.

b. Calling the 3D model by the computer software.

c. Modifying the 3D model according to your printer dimensions through Scaling, Rotating and other options.

d. Slicing the 3D model using different slicer like CuraEngine, Slic3r, Slic3r Prusa Edition and others. This process slices the $3 \mathrm{D}$ model to different layers and each layer is converted to $\mathrm{X} Y \mathrm{Z}$ coordinates known as G-codes that are used to drive the motors.

e. Now, the printer is ready to print the first 3D printing.

The block diagram showing the system functionality of 3D printer system is shown as in Figure 14.

The developed 3D printer as shown in Figure 15. The product printed with proposed design of the 3D printer model is found to be matching the 3D model by $(90 \%)$ as shown in Figure 16. The main specification of the presented 3D printer are: the FDM print Technology, the build volume: $100 * 160 * 200 \mathrm{~mm}$ (X Y Z), the layer resolution: $0.1 \mathrm{~mm}$, the filament diameter: $1.75 \mathrm{~mm}$, the nozzle diameter: $0.4 \mathrm{~mm}$, heated bed: 12 v/144 watt PCB heat bed, build surface: power supply: DC 12 v/240 watt, product Weight: $13.208 \mathrm{Kg}$, product dimension: 442L, 353W, 461H (Dimensions are in mm), input format: .stl, speed (mm/s): 20-200, filament type: PLA and SD card compatible.

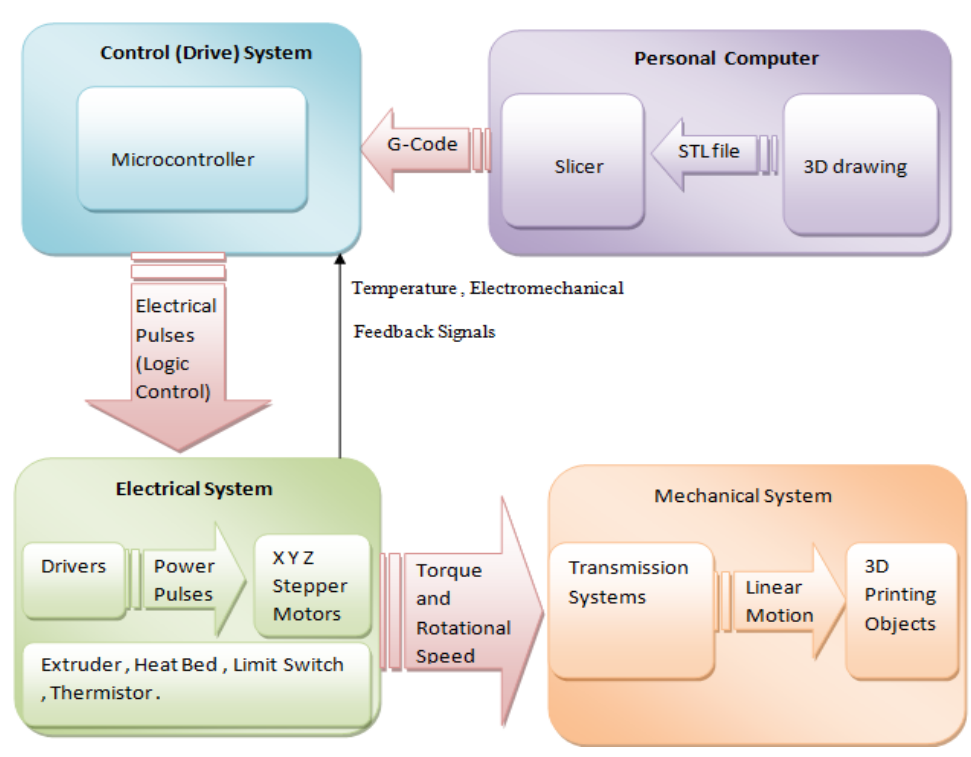

Figure 14. Block Diagram of 3D Printer System

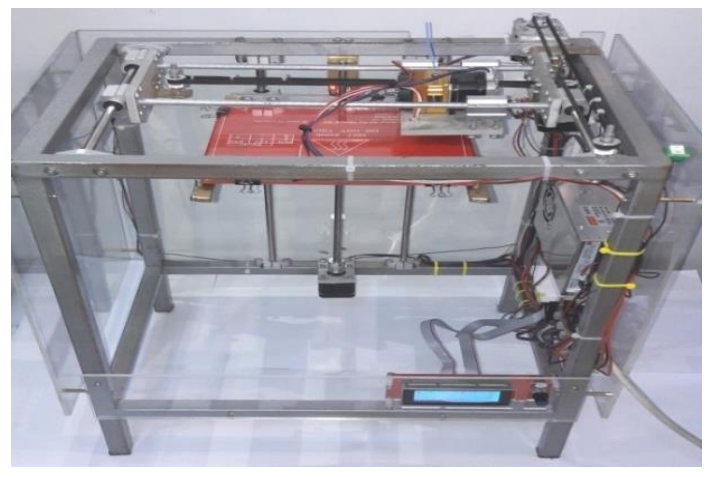

Figure 15. The developed 3D printer

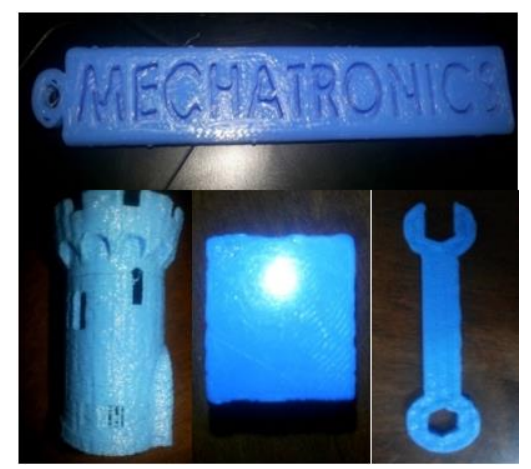

Figure 16. Some of products printed by the developed 3D printer 


\section{CONCLUSION}

3D printing is moving in several directions at this time and all indications are that it will continue to expand in many areas in the future. Some of the most promising areas include medical applications, custom parts replacement, and customized consumer products. As materials improve and costs go down, other applications we can barely imagine today will become possible. The designed prototype was successfully implemented step by step in addition tested to print different 3D printing jobs. Results of the printed objects by the implemented 3D printer found to be highly matching the 3D model by an about $90 \%$. As well the developed printed found to be operatedsmoothly with satisfactoryoperation.

\section{REFERENCES}

[1] Berman B., "3-D printing: The new industrial revolution. Business Horizons," vol. 55(2), pp. 155-162, 2012.

[2] Conner B.P., et al., "Making sense of 3-D printing: Creating a map of additive manufacturing products and services, " Additive Manufacturing, vol. 1-4, pp. 64-76, 2014.

[3] Majeed A., et al., "Developing of a manufacturing cycle architecture for fused deposition modeling technique," International Journal of Lightweight Materials and Manufacture, 2019.

[4] Albreem, M.A.M., et al., "Green internet of things (IoT): An overview," in 2017 IEEE 4th International Conference on Smart Instrumentation, Measurement and Application (ICSIMA). 2017.

[5] Stoukatch, S., et al., "Additive low temperature 3D printed electronic as enabling technology for IoT application," in 2017 IEEE 19th Electronics Packaging Technology Conference (EPTC). 2017.

[6] Salah, W.A., et al., "Implementation of PWM control strategy for torque ripples reduction in brushless DC motors," Electrical Engineering, vol. 97(3), pp. 239-250, 2015.

[7] Wu P., J. Wang, and X. Wang, "A critical review of the use of 3-D printing in the construction industry," Automation in Construction, vol. 68, pp. 21-31, 2016.

[8] Ragab D. and T.A. Tutunji, "Mechatronic system design project: A 3D printer case study," in 2015 IEEE Jordan Conference on Applied Electrical Engineering and Computing Technologies (AEECT), IEEE, 2015.

\section{BIOGRAPHIES OF AUTHORS}

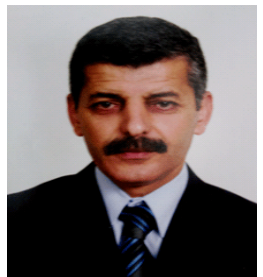

Ghazi qaryouti; received his B.Sc. in electrical Engineering from Damascus university in 1982, and M.S in Mechatronics Engineering from Al-Balqa' Applied University Jordan in 2006, and Ph.D. degrees in Mechatronics Engineering from De Montfort University in Leicester, UK in 2015. His research interests are in Power Electronics and Electric Drives, Energy Efficiency and Management, and Renewable System.

Email:ghazi_qaryouti@bau.edu.jo

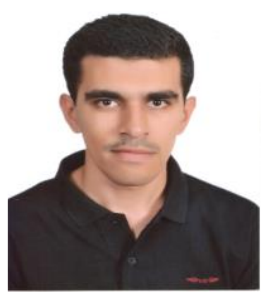

Abdel Rahman Salbad: Was born in Amman, Jordan in 1993, received his B.Sc. in Mechatronics Engineering from Al-Balqa' Applied University Jordan in 2018. He implemented two Mechatronics system projects: Design and Manufacturing of Three Dimensions (3D) Printer, Design and Manufacturing of Plasma - Oxy fuel Gantry CNC Machine. Currently, he is working as 3D Printers and CNC Machines Designer

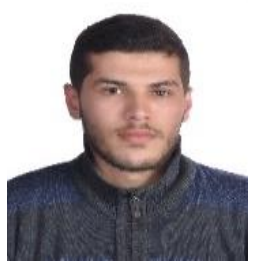

Sohaib A. Tamimi: received his B.Sc. in Mechatronics Engineering from Al-Balqa' Applied University, Amman, Jordan in 2018. His research interests are in 3D printers and CNC Oxy-Fuel cutter machines design, and works in instruments and measurement devise installation and calibration. 

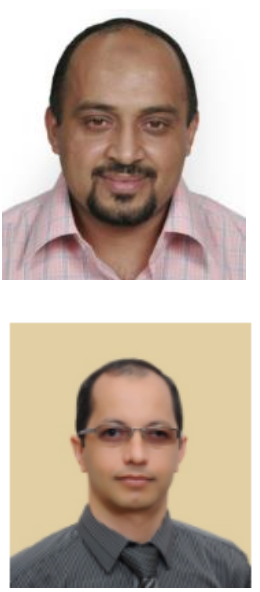

Wael A. Salah was born in Hebron, Palestine in 1978. He received his Bachelor degree in Electrical and Computer Engineering from Palestine Polytechnic University in 2001. $\mathrm{He}$ obtained his MS and $\mathrm{PhD}$ degrees in Electrical and Electronic Engineering from Universiti Sains Malaysia in 2007 and 2012, respectively. Currently, he is an associate professor at Palestine Technical University - Kadoorie (PTUK). His research interests include power electronics and electric drives, energy management

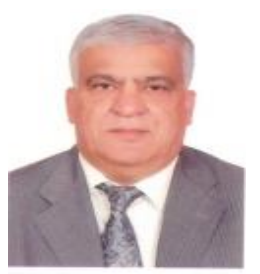

Qazem Jaber: received his M.S. and Ph.D. degrees in Electrical Drive and Automation Engineering from Moscow Power Institute in 1982 and 1986 respectively. Currently Dr. Qazem Jaber an Professor at Department of Mechatronics Engineering, Al-Balqa' Applied University Jordan. His research interests are in Power Electronics and Electric Drives, Energy Efficiency and Management, and Renewable System. 